\title{
Figuras paternas,
}

\section{Constitución alemana}

\section{y Convención Europea \\ de los Derechos Humanos*}

\author{
MARTIN LÖHNIG**
}

\section{Introducción}

El derecho interno en materia de infancia y filiación en cada uno de los Estados miembros del Consejo de Europa, como se mostrará a continuación para el caso del derecho alemán, tiene que ajustarse al artículo 8 numeral i de la Convención Europea de los Derechos Humanos (en adelante, cEDH o "la Convención"), la cual rige para todos y cada uno de ellos. El artículo en mención establece que "toda persona tiene el derecho al respecto de su vida privada y familiar, de su domicilio y de su correspondencia", a lo que hay que añadir el artículo i4 de la misma Convención, que prohíbe toda discriminación, por ejemplo, en razón del sexo, de nacimiento o de cualquier otra condición ${ }^{\mathrm{T}}$. Toda persona está legitimada

* Trad. del alemán: Catalina Salgado Ramírez. Título original: "Vaterfiguren, Deutsches Grundgesetz und Europäische Menschenrechtskonvention".

Fecha de recepción: 15 de diciembre de 2015. Fecha de aceptación: 9 de octubre de 2016.

Para citar el artículo: M. LöHNig, "Figuras paternas, Constitución alemana y Convención Europea de los Derechos Humanos", Revista de Derecho Privado, Universidad Externado de Colombia, n. ${ }^{\circ}$ 3I, julio-diciembre de 20I6, 377-383. DoI: http://dx.doi.org/IO.I860I/or 234366.n3I.I 4

** Doctor en Derecho por la Universität Regensburg, Regensburg, Alemania. Profesor catedrático de Derecho Privado e Historia del Derecho Alemán y Europeo, Universidad de Regensburg, Regensburg, Alemania. Contacto: martin.loehnig@ur.de

I (Nota de trad.) El texto del artículo I4 CEDH es del siguiente tenor: "El goce de los derechos y libertades reconocidos en el presente Convenio ha de ser asegurado sin distinción alguna, especialmente por razones de sexo, raza, color, lengua, religión, opiniones políticas u otras, origen nacional o social, pertenencia a una minoría nacional, fortuna, nacimiento o cualquier otra situación". 
para demandar ante el Tribunal Europeo de Derechos Humanos (en adelante, TEDH o "el Tribunal"), con sede en Estrasburgo, por las violaciones a los derechos establecidos en la Convención que sean cometidas por un Estado parte, el cual a su vez puede ser sancionado por el mismo Tribunal. La Constitución alemana contiene disposiciones similares. El artículo 6 numeral i pone al matrimonio y a la familia bajo la especial protección del ordenamiento estatal; el numeral 2 del mismo artículo declara como derecho natural de los padres el cuidado y crianza de los hijos, y ante todo lo establece como un deber vinculante; y el numeral 5 exige que tanto los hijos matrimoniales como los extramatrimoniales gocen de las mismas condiciones para su desarrollo físico y emocional, y de la misma posición en la sociedad; todo ello en armonía con el artículo 3 de la Constitución, que establece el derecho a la igualdad.

En tiempos recientes, la República Federal Alemana ha sido condenada en repetidas ocasiones por parte del TEDH por cuenta de su derecho de familia. Los fallos, que fundamentalmente se ocupan de reglas específicas sobre el derecho de custodia y de trato (visita), y en parte también del derecho de sucesiones, pueden ser reducidos en últimas, en su núcleo, al campo del derecho de filiación.

\section{Sobre el rol del Tribunal Europeo de Derechos Humanos en el ordenamiento jurídico alemán}

Respecto de la relación entre derecho internacional y derecho nacional se sostiene en el derecho público alemán, de manera predominante ${ }^{2}$, la teoría dualista, a la que adhirió también la Corte Constitucional alemana en el fallo Görgülu I³ .

2 Cfr. Stein/Frank, Staatsrecht, $20 \mathrm{IO}^{2 \mathrm{I}}, \$ 5,26 \mathrm{ss.}$

3 BVerfG, Decisión del I4.I0.2004, Az. 2 BvR I48I/04, citada en juris BVerfGE I I I, $207=\mathrm{Fa}_{-}$ mRZ 2004, I857. (Nota de trad.) Con antelación a esta decisión, alegó el demandante ante el TEDH que la decisión del tribunal alemán (en apelación) que le denegaba el derecho a la custodia de su hijo era violatoria del derecho a su vida familiar de acuerdo con el artículo 8 cEDH. Los hechos, según la sentencia del TEDH, son los siguientes: el demandante vino a saber del embarazo de su ex pareja tiempo después de que la relación había terminado y convinieron que él se haría cargo de la criatura. Sin embargo, habiéndose dado el nacimiento, la madre dio en adopción al hijo sin que el padre hubiera podido tener contacto con la madre desde el embarazo. Cuando el padre se enteró del nacimiento y de que el menor había sido dado en adopción quiso adoptarlo, pero el bebé a los pocos días de nacido había sido ya entregado a una pareja. El demandante inició los procedimientos de reconocimiento de paternidad y solicitó que se le otorgara la custodia temporal del menor y se estableciera un régimen de visitas. Si bien hubo lugar al establecimiento de visitas por parte del demandante a su hijo, los padres adoptivos, luego de un periodo de enfermedad del menor, consideraron que tales visitas no eran convenientes para el bienestar del niño. Aunque en primera instancia se concedió al padre la custodia del hijo, en apelación se revocó la custodia y además se suspendió el derecho de trato del padre, sobre la base de que transferir la custodia al padre iba en contra del bienestar del menor: separarlo de la familia con la que vivía hasta el momento y con la que había construido sólidos vínculos familiares podía ser perjudicial él. El Tribunal Constitucional alemán no aceptó la queja de inconstitucionalidad del demandante (200I) y este recurrió entonces al TEDH. Habiendo condenado este a Alemania en Sentencia de 26 de febrero de 2004, surgió el problema de la vinculatoriedad de la decisión del 
La Constitución Política se basa claramente en la concepción clásica según la cual, tratándose de la relación entre derecho internacional y derecho nacional, se está de frente a dos ámbitos jurídicos distintos, y la naturaleza de esta relación, desde el punto de vista del derecho interno, solamente puede ser determinada a partir del derecho interno mismo; esto resulta del tenor de los arts. 25 y 59 inc. 2 de la Constitución Política ${ }^{4}$.

La CEDH, a pesar de su inicial carácter de derecho internacional, tiene en Alemania, debido a la ley de transformación (Transformationsgesetz), el rango de una simple ley estatal, y es en razón de esta vinculante para los jueces 5 . Como tratado de derecho internacional público la Convención vincula a Alemania frente a los otros Estados signatarios (no frente a los ciudadanos alemanes, porque estos no son parte en la Convención) y la obliga a implementar en Alemania un ordenamiento jurídico acorde con el contenido de la propia Convención.

Pueden surgir conflictos entre el contenido de la CEDH y el de la Constitución Política debido a la diversidad de las garantías fundamentales que ellas establecen. Como recientemente ha puesto de presente el juez constitucional Ferdinand Kirchhof, la Convenión, "debido a su validez inmediata como tratado en Alemania, no puede ser reducida al ámbito de la mera voluntad política sin fuerza normativamente vinculante. No obstante, los derechos fundamentales alemanes gozan de aplicación preferente"6. Según el magistrado, una discrepancia tendría que ser resuelta "mediante un diálogo entre tribunales".

TEDH para el juez local que denegó la custodia: la decisión fue objeto de recurso por parte del tribunal de segunda instancia, bajo el argumento de que ella condenaba al Estado alemán, y que no era el juez local el destinatario de la orden. Así las cosas, recurrió el demandante nuevamente ante el Tribunal Constitucional, el cual se pronunció acogiendo la teoría dualista señalada por el autor de este escrito. Sin embargo, valga anotar lo que señala la sentencia en su aparte i párrafo 30: "En el sistema legal alemán, la CEDH tiene el estatus de una ley federal y debe ser tomada en consideración para interpretar el ordenamiento nacional, incluyendo los derechos fundamentales y las garantías constitucionales. El efecto vinculante de una decisión del TEDH se extiende a todas las autoridades estatales y en principio les impone una obligación, en el ámbito de su jurisdicción y sin violación del derecho vinculante (art. 30.3 de la Ley Fundamental), de dar por terminada una continua violación de la Convención y de crear una situación que cumpla con ella. [...] Las cortes están, en todos los eventos, en el deber de tomar en consideración una decisión que tiene que ver con un caso ya decidido por ellas, y en todo caso se encuentran obligadas, cuando por medio de una vía procesalmente permitida deben decidir nuevamente sobre la cuestión y están en la capacidad de acatar el fallo sin violación del derecho sustancial".

4 BVerfG, Decisión del I4.I0.2004, Az. 2 BvR I48I/O4, Rz. 34, citada en juris = FamRZ 2004, I 857, I 859 .

5 Schlaich/Ковіотн, Das Bundesverfassungsgericht, $2010^{8}$, Cuarta Parte, Rz. 368.

6 Ківснноғ, F., „Grundrechtsschutz durch europäische und nationale Gerichte“, en NFW 20 I I, 368 I, 3683. En muchos otros Estados miembros del Consejo de Europa la cEDH goza de una posición jurídica muy distinta: sólo en la menor parte de los Estados puede un ciudadano como en Alemania- someter al tribunal constitucional nacional el control del contenido de las decisiones de los jueces. En algunos Estados miembros no existe un tribunal constitucional independiente, y en la mayoría de los Estados miembros el derecho de los ciudadanos se limita 


\section{Constitución Política y Convención Europea de los Derechos Humanos: aspectos en común y diferencias}

¿Cómo se presenta en concreto este "diálogo entre los tribunales"? Ambos tribunales parten de posiciones de base idénticas: en los procesos de custodia y de regulación de visitas deben ser sopesados los intereses de todos los implicados. Criterio determinante es el bienestar del menor (Kindeswobl) 7 .

La exclusión del trato entre el menor y uno de sus padres solamente se admite bajo estrictas condiciones, ya que el bienestar del menor está en función de poder mantener sus relaciones familiares ${ }^{8}$. Sin embargo, el derecho de trato o visita (Umgansrecht) tiene su límite allí donde su ejercicio pueda poner en peligro concreto el bienestar del menor ${ }^{9}$. Con todo, ambos tribunales siguen llegando a resultados distintos, en particular cuando se trata de la posición jurídica del padre extramatrimonial (nichtehelicher Vater) o del padre biológico.

\section{Posición jurídica del padre extramatrimonial (nichtebelicher Vater)}

Se dio una primera discrepancia, luego de que el Tribunal Constitucional decidiera en un fallo del año I98 ${ }^{\left[{ }^{[\circ}\right]}$, sobre el (hoy derogado) $\$$ I 7 I I вGB, que, con miras a un desarrollo imperturbable del menor, al padre extramatrimonial solo pueda serle concedido el derecho de visita cuando este sirva al bienestar del menor. El TEDH, en una decisión del año $200 \mathrm{I}^{[\mathrm{II}]}$, consideró esta norma (que en el entretanto ha sido derogada) como una discriminación inadmisible en contra del padre no matrimonial. Según el Tribunal, sería contrario a derecho no considerar prima facie como dirigido al bienestar del menor el trato entre este y su padre no matrimonial, y sólo decretarlo de manera excepcional contra la voluntad de la madre. El mismo tribunal equiparó a los padres divorciados y a los padres extramatrimoniales y exigió para la justificación de un trato diferencial la presencia de un "motivo de extrema relevancia" I2.

a hacer valer la inconstitucionalidad de las normas de derecho aplicable. En muchos Estados el TEDH ha asumido en parte la función que tradicionalmente cumple en Alemania el Tribunal Constitucional.

7 TEDH, fallo de I0.2.20 I I (Tsikakis v. Deutschland), FamRZ 20 I I, I I 25, I I 26 (num. 77); BVerfGE 3 I, I 94, 208 f.; BVerfGE 56, 363, 383 und 391; BVerfGE 84, I68, I 83.

8 TEDH, fallo de 26.2.2004 (Görgülï v. Deutschland), FamRZ 2004, I456, I459 (num. 48 ss.); BVerfGE 31, I94, 209; BVerfGE 64, I80, I 88 у г 9 I.

9 TEDH, fallo de 26.2.2004 (Görgïlii v. Deutschland), FamRZ 2004, I456, I 459 (num. 43); BVerfGE 64, I80, I9I.

Iо BVerfGE $56,{ }_{3}^{6} 6_{3}, 39$ I y 393 .

I I TEDH, fallo del i i.ro.200 I - 34045/96 (Hoffmann v. Deutschland), juris (num. 53).

I2 TEDH, fallo del I I. IO.200 I - 34045/96 (Hoffmann v. Deutschland), juris (num. 56). 
Sin embargo, en el año 2003 el Tribunal Constitucional alemán consideró conforme al ordenamiento ${ }^{13}$ el $\$$ I 626 a inciso I numeral I BGB ${ }^{\mathrm{I}}$, el cual cierra las puertas a una patria potestad del padre no esposado con la madre en caso de que ella no esté de acuerdo. El TEDH criticó esta disposición en el año $2009^{[5]}$, sobre la base no solo del artículo $8 \mathrm{CEDH}$, sino también de una comparación entre la posición jurídica de los padres no casados y los padres de hijos matrimoniales divorciados o separados de cuerpos; es decir, sobre la base de los artículos 8 y ${ }^{1} 4 \mathrm{CEDH}^{16}$. Algunos meses después, el Tribunal Constitucional alemán concedió al padre no matrimonial el derecho de solicitar que judicialmente se revise si en el caso concreto está justificada una exclusión de su patria potestad en razón del bienestar del menor ${ }^{17}$. Concordancia entonces sólo hubo en el resultado: el Tribunal Constitucional basó su decisión fundamentalmente en el derecho a la paternidad del padre no casado de conformidad con el artículo 6 inciso 2 de la Ley Fundamental.

\section{Posición jurídica del padre biológico}

Las posiciones del TEDH y del Tribunal Constitucional alemán se diferencian así mismo en lo que tiene que ver con la situación jurídica del padre biológico, cuyo hijo legalmente tiene por padre a otra persona. Para el Tribunal Constitucional, según una sentencia de $2003^{[18]}$, un padre biológico y su hijo constituyen familia en el sentido del artículo 6 inciso I de la Ley Fundamental sólo en la medida en que entre ellos exista una relación socio-familiar. Ello refleja el contenido del $\S$ I 684 inciso I BGB ${ }^{\mathrm{I} 9}$, según el cual un padre reconocido legalmente como tal está sin más legitimado y obligado al trato con su hijo/a, mientras que un padre biológico sólo lo está, según el $\$ \mathrm{I} 685$ inciso $2 \mathrm{BGB}^{20}$, cuando entre él y su hijo/a ya

I3

\section{4}

El parágrafo $\$$ s 6260

raciones sobre la custodia y patria potestad. Inc. I. Si para la fecha del nacimiento los padres no están casados entre ellos, entonces tienen ellos la patria potestad conjunta: I. Cuando ellos declaran que quieren ejercer conjuntamente la patria potestad. 2. Cuando posteriormente contraen matrimonio. 3. Cuando un tribunal concede el ejercicio conjunto de la patria potestad".

I5 TEDH, fallo del 3.I 2.2009 (Zaunegger v. Deutschland), FamRZ 2010, 103, I05 s.

I6 TEDH, fallo del 3.1 2.2009 (Zaunegger v. Deutschland), FamRZ 2010, Iо3, Io6 (num. 43 s. y 6r s.)

I7 BVerfG FamRZ 2010, I403, I 406 ss.

I8 BVerfG FamRZ 2003, 816, 822.

I9 (Nota de trad.) $\$$ I684 inc. I BGB: "El menor tiene el derecho al trato con cada uno de sus padres. Los padres están obligados y autorizados al trato con su hijo/a".

20 (Nota de trad.) $\$$ г 685 в вв. "Trato del menor con otras personas de referencia. (I) Abuelos y hermanos tienen un derecho de trato con el menor cuando este trato sirve al bienestar del menor. (2) Lo mismo vale para personas de referencia cercanas al menor, cuando éstas se encargan o se han hecho cargo del menor (relación socio-familiar). Se entiende por lo general que alguien se ha hecho cargo del menor, cuando ha habido lugar a una prolongada convivencia doméstica...". 
existe una relación socio-familiar, es decir, cuando el padre se hace o se ha hecho cargo de hecho del menor.

El TEDH no aceptó esta diferenciación generalizadora. Según el Tribunal, si bien es cierto que un padre cuya paternidad no ha sido jurídicamente reconocida no podría ampararse de manera automática en el artículo $8 \mathrm{CEDH}$ si no ha habido ningún contacto con el menor, no obstante, de manera excepcional, también podría entrar en el ámbito de protección de este artículo la intención de establecer una vida familiar, siempre que el padre biológico no sea quien haya dado lugar a que una vida familiar no haya tenido lugar ${ }^{2 \mathrm{I}}$. Por ello, en opinión del TEDH, el derecho de trato de un padre biológico no podría hacerse depender, de manera tan tajante, de la preexistencia de una relación socio-familiar, sino que tendría que ser decidido de acuerdo con un examen del bienestar del menor en el caso concreto. De no ser así, los padres jurídicamente reconocidos como tales tendrían en sus manos el poder de impedir la formación de una relación sociofamiliar, al prohibirle al padre biológico todo contacto con el menor, sin que, por el contrario, tal actitud defensiva tenga que estar fundada en un motivo relevante relativo al bienestar del menor ${ }^{22}$. Según la opinión del TEDH, es irrelevante incluso que la paternidad biológica se encuentre en disputa entre los interesados. Como consecuencia, el legislador alemán promulgó el § I686a BGB²3, que garantiza al padre biológico un derecho de trato cuando ha demostrado un interés persistente en el menor y el trato va en pro de su bienestar. Con la mención del criterio de la "demostración de interés", por primera vez se acoge en el derecho de familia alemán un criterio desarrollado por el TEDH en aplicación del artículo 8 CEDH.

\section{Bienestar del menor vs. bienestar del menor}

Trasfondo de estas diferencias entre ambos altos tribunales lo constituye el que sólo coinciden superficialmente en las premisas. Ambos tribunales consideran el criterio del bienestar del menor como criterio decisivo, pero atribuyendo a este un contenido diferente: el concepto genético de bienestar del menor acuñado por el TEDH se tropieza con el concepto social de bienestar del menor concebido

2 I TEDH, fallo del 2 I.r 2.20Iо (Anayo v. Deutschland), FamRZ 201 I, 269 (Rn. 57); TEDH, fallo del I 5.9.20 I I (Schneider v. Deutschland), FamRZ 20 I I, I 7 I 5 f. (Rn. 8I).

22 TEDh, fallo del 2 I.r 2.20Iо (Anayo v. Deutschland), FamRZ 20 I , 269, 27 I (num. 69); cfr. TEDH, fallo del I 8.3.2008 (Hülsmann v. Deutschland), NJw-RR 2009, I 585 , I 587 .

23 (Nota de trad.) § I686a BGB: "Derechos del padre carnal, no reconocido legalmente como padre. (I) Siempre que exista el reconocimiento de la paternidad a otra persona, el padre carnal, que haya demostrado un interés serio en el menor tiene los siguientes derechos: I. Un derecho al trato con el menor, cuando el trato sirva al bienestar del menor, y 2. Un derecho a recibir información, por parte de cada uno de los padres reconocidos legalmente como tales, acerca de las condiciones personales del menor, siempre que tenga un interés justificado y esto no perjudique el bienestar del menor...". 
por el Tribunal Constitucional alemán. El TEDH parte de la asunción de que el trato con el padre genético está siempre en función del bienestar del menor. Las circunstancias concretas de vida del menor en el caso concreto no parecen tener una relevancia reconocible en los fallos correspondientes; no se mencionan ni una sola vez, ni menos aún son calificadas en concreto. El bienestar del menor, que con tal toma de posición resulta equiparado a la pretensión del padre genético, se convierte así en una verificación objetiva en mero interés del padre genético. Este modelo de pensamiento puede resumirse de la siguiente manera: el bienestar del menor se protege, en principio, sólo cuando el padre genético goza de derechos en relación con el hijo, es decir, cuando el principio biológico, en principio, prevalece; cuando, en últimas, bienestar del menor e interés del padre biológico se llevan a unidad.

El Tribunal Constitucional alemán (y de la mano de este el legislador alemán, ya con la emanación de los $\$ \$$ г 684 y г 685 вGB) también se basó en el criterio de bienestar del menor: un derecho de trato del que es sólo padre biológico únicamente entra en juego -como, por lo demás, tratándose de toda persona de referencia para el menor- cuando este ha asumido una responsabilidad de hecho hacia al menor (relación socio-familiar) según el $\$$ I 685 inciso 2 BGB ${ }^{24}$. Así las cosas, la posición jurídica del padre genético es regulada de manera coherente con la posición jurídica de otras personas de referencia. Para el derecho alemán, una mera relación genética entre un hombre y su hijo o hija no es nunca suficiente para fundar una relación de trato, mientras sí lo es una relación social entre un hombre no genéticamente relacionado y un menor. La entrada en vigor del

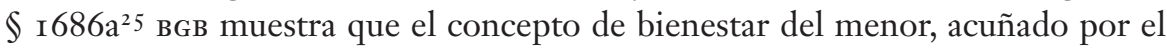
TEDH, comienza a imponerse. En todo caso, esto parece estar muy lejos de constituir un "diálogo".

24 (Nota de trad.) Ver supra nota 20.

25 (Nota de trad.) Ver supra nota 23. 